\title{
A PROPÓSITO DE LA SENTENCIA DEL TRIBUNAL CONSTITUCIONAL “CASO QUIMPER” Y LA LIBERTAD DE INFORMACIÓN
}

\author{
GONZÁLEs OJEDA, Magdiel ${ }^{1}$
}

SUMARIO: I.- Antecedentes. II.- Los fundamentos de la sentencia del Tribunal Constitucional. 2.1 Naturaleza de la prueba prohibida. 2.2 El fundamento de la prueba prohibida. 2.3 La prueba prohibida en la Constitución. 2.4 Los efectos de la prueba prohibida. 2.5 Interceptación y grabación de las conversaciones telefónicas. III.- La libertad de información y la Sentencia del Tribunal Constitucional. 3.1. Contenido de la libertad de información. 3. 2. El derecho a la información. 3.3. La libertad de información y el mandato del Tribunal Constitucional en la Sentencia del Expediente $\mathrm{N}^{\circ}$ 00655-2010-PHC/TC. IV. Reflexiones finales.

\section{I.- Antecedentes}

Según aparece del expediente $N^{\circ}$ 00655-2010-PHC/TC., doña Carmen Luisa Castro Barrera de Químper, interpuso demanda de hábeas corpus a favor de su esposo don Alberto Químper Herrera, solicitando que se declare nulo el auto de apertura de instrucción de fecha 21 de octubre de 2008, emitido en el Expediente $\mathrm{N}^{\circ} 107-2008$, por el Tercer Juzgado Especial de Lima, y que, en consecuencia se ordene dictar un auto denegando la instrucción. Fundamenta su pedido afirmando que el auto de apertura de instrucción viola el derecho al debido proceso de su esposo y señala que la calificación de los ilícitos penales atribuidos a su esposo se fundamenta en pruebas obtenidas con afectación de su derecho al secreto y a la inviolabilidad de las comunicaciones, (artículo 2.10 de la Constitución).

Como fundamento de hecho, la demandante, sostiene que "con fecha 5 de octubre de 2008, el programa televisivo "Cuarto Poder" difundió cuatro audios ex-profesamente editados y que días después el diario "La República” también presentó nueve audios exprofesamente editados y obtenidos con vulneración del derecho al secreto y a la inviolabilidad de las comunicaciones (artículo 2.10 de la Constitución), por cuanto son conversaciones interceptadas del favorecido que han sido arbitrariamente reproducidas, editadas y descontextualizadas", con lo que concluye que no pueden servir de sustento probatorio del auto de apertura cuestionado.

El Tribunal Constitucional al delimitar la pretensión y la materia controvertida, sostiene "que la demanda tiene por objeto se declare la nulidad del auto de apertura de instrucción, de fecha 21 de octubre de 2008, emitido por el juzgado emplazado en el

${ }^{1}$ Presidente de la Comisión Organizadora del la Facultad de Derecho de la Universidad Ricardo Palma, Ex magistrado del Tribunal Constitucional, Doctor en Derecho Público. 
Expediente N. ${ }^{\circ}$ 107-2008, en virtud del cual se resolvió abrir instrucción en contra del beneficiario como presunto autor de los delitos de patrocinio ilegal, de cohecho pasivo propio y de tráfico de influencias, y como presunto cómplice primario del delito de negociación incompatible", afirma asimismo, "Se alega que el auto de apertura cuestionado afecta los derechos al secreto y a la inviolabilidad de las comunicaciones y al debido proceso del beneficiario, en conexión con su derecho a la libertad individual, por cuanto las pruebas de cargo que sustentan el auto de apertura de instrucción son pruebas prohibidas, toda vez que son producto de interceptaciones telefónicas” (artículo 2.10 de la Constitución).

Sigue el Tribunal señalando que "En dicha línea argumentativa, también se pretende que se le ordene al juez emplazado que en el Expediente. $\mathrm{N}^{0}$ 107-2008 dicte a favor del beneficiario un auto denegatorio de instrucción, debido a que no existen pruebas lícitas que sustenten la instrucción que se le sigue”.

Finalmente concluye que, "Delimitadas las pretensiones y los alegatos que sustentan la demanda, este Tribunal considera necesario pronunciarse sobre algunas cuestiones que plantea la denominada prueba prohibida en el proceso penal, también conocida en la doctrina como prueba ilícita o prueba inconstitucional. Para ello, se habrán de responder las siguientes interrogantes ¿cuál es la naturaleza jurídica de la prueba prohibida?; ¿la prueba prohibida es un derecho constitucional explícito, un derecho constitucional no enumerado o es el contenido implícito de un derecho constitucional?; y ¿qué efectos genera la prueba prohibida en el proceso penal?"; por tales razones, determina que analizará el contenido del derecho al secreto y a la inviolabilidad de las comunicaciones, así como sus límites, debido a que en la demanda se alega que se habría producido la presunta vulneración de este derecho".

\section{II.- Los fundamentos de la sentencia del Tribunal Constitucional}

La sentencia del expediente n. 00655-2010-PHC/TC, expedida por el Tribunal Constitucional, en el primer fundamento, se refiere al contenido del derecho al secreto y a la inviolabilidad de las comunicaciones, así como sus límites, debido a que en la demanda se alega que se habría producido la presunta vulneración de este derecho; en tal razón el Tribunal, aborda los temas en los fundamentos de la sentencia. siguientes: la naturaleza jurídica de la prueba prohibida, el fundamento de la prueba prohibida, la prueba prohibida en la Constitución, los efectos de la prueba prohibida, y la interceptación y grabación de las conversaciones telefónicas.

\subsection{Naturaleza jurídica de la prueba prohibida}

$\mathrm{Al}$ analizar éste primer argumento, el Tribunal Constitucional sostiene que "En la dogmática y jurisprudencia constitucional comparada no existe consenso para determinar cuál es la naturaleza jurídica de la prueba prohibida”; en tal sentido, afirma por una parte que "existen posiciones que consideran a la prueba prohibida como una garantía objetiva 
del debido proceso penal que es absoluta y que resulta aplicable a cualquier clase de procedimiento o proceso", y "como muestra de que en algunos ordenamientos la prueba prohibida es considerada como una garantía objetiva del debido proceso penal, el Tribunal cita a la fracción IX, del inciso a, del artículo $20^{\circ}$ de la Constitución Política de los Estados Unidos Mexicanos que dispone que el proceso penal se regirá, entre otros, por el principio de que "Cualquier prueba obtenida con violación de derechos fundamentales será nula”.

Tratando de reafirmar lo expresado en la argumentación antes referida, el Tribunal dice que "existen otras posiciones que predican que la prueba prohibida es un auténtico derecho fundamental que garantiza que el medio probatorio prohibido no sea admitido, ni actuado o valorado en el proceso penal como prueba de cargo, pero que, como todo derecho fundamental, admite limitaciones en su ejercicio".

Asimismo, el Tribunal Constitucional señala que, en el ámbito de la jurisdicción constitucional, también se tienen decisiones contrarias respecto de la admisión de la prueba prohibida, en tal sentido destaca que en "alguna oportunidad el Tribunal Constitucional español consideró que la prueba prohibida no era un auténtico derecho constitucional”; así lo determinó en el “Auto 289/1984, del 16 de mayo de 1984", referido al principio de prohibición de utilizar los medios de prueba ilícitamente obtenidos "no se apoya en ninguna norma de derecho positivo ni de la Constitución, ya que no existen disposiciones legales en qué apoyar tal principio y doctrina”.

En su argumentación, sobre la naturaleza jurídica de la prueba prohibida, recurre a la jurisprudencia del propio Tribunal y cita el acápite 3.b) Momento de postulación de la prueba, de la sentencia del expediente $\mathrm{N}^{\circ}$ 06712-2005-PHC/TC, Caso Magaly Medina, en la parte que se refiere “(...) entre otros principios, el medio probatorio debe contar con: Licitud: es decir que "No pueden admitirse medios probatorios obtenidos en contravención del ordenamiento jurídico, lo que permite excluir supuestos de prueba prohibida”.

Igualmente, el Tribunal Constitucional menciona el acápite 2.5 La integridad personal y los medios de prueba judicial, de la Resolución del expediente $\mathrm{N}^{\circ}$ 02333-2004-PHC/TC., referido a que el derecho a la prueba se encuentra sujeto a determinados principios, como que su ejercicio se realice de conformidad con los valores de pertinencia, utilidad, oportunidad y licitud.

Finaliza, esta parte el Tribunal, con la referencia a la jurisprudencia norteamericana y nos habla de la regla de exclusión de la prueba obtenida con violación de derechos fundamentales. Concluye, el Tribunal Constitucional, éste parágrafo, afirmando que "en la dogmática y jurisprudencia comparada resulta variable la naturaleza jurídica que se le pretende atribuir a la prueba prohibida. Pero, además, agrega inmediatamente que (...) en consideración de este Tribunal la prueba prohibida es un derecho fundamental que no se 
encuentra expresamente contemplado en la Constitución, que garantiza a todas las personas que el medio probatorio obtenido con vulneración de algún derecho fundamental sea excluida en cualquier clase de procedimiento o proceso para decidir la situación jurídica de una persona, o que prohíbe que este tipo de prueba sea utilizada o valorada para decidir la situación jurídica de una persona. En este sentido, debe destacarse que la admisibilidad del medio probatorio en cualquier clase de procedimiento o proceso no se encuentra únicamente supeditaba a su utilidad y pertinencia, sino también a su licitud”2.

\subsection{El fundamento de la prueba prohibida}

En presente acápite, el Tribunal inicia su argumentación refiriendo que en “(...) relación al fundamento que garantiza la inadmisión, inutilización o exclusión de la prueba prohibida en cualquier clase de procedimiento o proceso para decidir la situación jurídica de una persona, (...) en la dogmática constitucional comparada no existe consenso para concluir que el derecho a la inadmisión, inutilización o exclusión de la prueba prohibida tiene un único fundamento".

En este contexto, nos refiere que, "existen posiciones que consideran que la inutilización de la prueba prohibida encuentra sustento en el contenido del derechoprincipio a la presunción de inocencia reconocido en el artículo 8.2 de la Convención Americana sobre Derechos Humanos, que a decir de la Corte Interamericana de Derechos Humanos, "exige que una persona no pueda ser condenada mientras no exista prueba plena de su responsabilidad penal. Si obra contra ella prueba incompleta o insuficiente, no es procedente condenarla, sino absolverla" [Caso Cantoral Benavides, sentencia del 18 de agosto de 2000, párr. 120]”.

Con la argumentación antes referida, sostiene el Tribunal que "la presunción de inocencia es la primera garantía del proceso penal que exige no sólo que exista una mínima actividad probatoria de cargo, sino también que la obtención de las fuentes de prueba se produzca sin la violación de algún derecho fundamental”. Asimismo, (...) considera que el fundamento de la inadmisión, inutilización o exclusión de la prueba prohibida para decidir la situación jurídica de una persona, se encuentra contenido en el derecho a la tutela procesal efectiva (debido proceso) o en las garantías judiciales indispensables para la protección de los derechos fundamentales previstas en el artículo $8^{\circ}$ de la Convención Americana sobre Derechos Humanos.

\subsection{La prueba prohibida en la Constitución}

El Tribunal Constitucional señala que nuestra Constitución Política del Estado regula expresamente lo referente a la prueba prohibida en su inciso 10) del artículo $2^{\circ}$; y la validez de las declaraciones obtenidas por: $a$ ) la violencia moral, psíquica o física; $b$ ) la tortura, y c) los tratos humillantes o denigrantes.

\footnotetext{
${ }^{2}$ El subrayado, es nuestro.
} 


\subsection{Los efectos de la prueba prohibida}

En esta temática el Tribunal Constitucional, reitera su línea argumentativa del proceso; es decir que se refiere ahora que "ámbito del proceso penal la consecuencia de la prueba prohibida se encuentra reconocida en el artículo $159^{\circ}$ del Nuevo Código Procesal Penal, al señalar que "[e]l Juez no podrá utilizar, directa o indirectamente, las fuentes o medios de prueba obtenidos con vulneración del contenido esencial de los derechos fundamentales de la persona”.

También, se refiere al ámbito constitucional, y vuelve a citar en la STC 023332004-HC/TC este Tribunal destacó que el literal h del inciso 24) del artículo $2^{\circ}$ de la Constitución prescribe que "el derecho a que se establezca la invalidez de las declaraciones obtenidas mediante el uso de la violencia en sentido lato" tiene "como fin enervar el valor jurídico de aquellas revelaciones o exposiciones alcanzadas mediante cualesquiera de las formas de agresión anteriormente señaladas”.

\subsection{Interceptación y grabación de las conversaciones telefónicas}

El Tribunal Constitucional, en este acápite trata sobre la interceptación y grabación de las conversaciones telefónicas y recurre para argumentar al respecto a la Sentencia de La Corte Interamericana de Derechos Humanos, de fecha del 6 de julio de 2009, en el Caso Escher y otros vs. Brasil, donde se precisa que el derecho a la vida privada previsto en el artículo $11^{\circ}$ de la Convención Americana sobre Derechos Humanos protege "las conversaciones realizadas a través de las líneas telefónicas instaladas en las residencias particulares o en las oficinas, sea su contenido relacionado con asuntos privados del interlocutor, sea con el negocio o actividad profesional que desarrolla”.

El Tribunal Constitucional, en su fundamento 20), con la argumentación sobre el Caso Escher y otros vs. Brasil, concluye que el "Estado debe investigar, juzgar y, en su caso, sancionar a los responsables de la violación del derecho a la vida privada del beneficiario, consistente en la interceptación y divulgación de sus conversaciones telefónicas, así como la entrega de las conversaciones telefónicas a los medios de comunicación”.

Pero, además, precisa al final del fundamento 20) ya referido que “(...) la divulgación de las grabaciones telefónicas requiere de la autorización de sus interlocutores para que se legítima”.

En el fundamento 22), el Tribunal Constitucional hace llamado para recordar lo que la Corte Interamericana de Derechos Humanos en la sentencia del Caso Escher y otros vs. Brasil, para manifestarnos que ha enfatizado que las conversaciones telefónicas son de carácter privado y no constituyen información pública, su divulgación requiere de la autorización de los interlocutores, caso contrario, su divulgación se torna ilegítima; refiere, también, el Tribunal, en su fundamento 23) el inciso 10) del artículo $2^{\circ}$ de la Constitución, que dispone que las (...) comunicaciones, telecomunicaciones o sus 
instrumentos sólo pueden ser abiertos, incautados, interceptados o intervenidos por mandamiento motivado del juez, con las garantías previstas en la ley.

Finalmente, el Tribunal Constitucional concluye "que los medios de comunicación social se encuentran prohibidos de divulgar o difundir interceptaciones y grabaciones de conversaciones telefónicas, salvo que exista la autorización de los interlocutores grabados para que sea conocida por terceros o un mandamiento judicial motivado que permita su difusión por ser de interés público, bajo responsabilidad”

\section{III.- La libertad de información y la Sentencia de Tribunal Constitucional.}

Como se puede observar, claramente, de la Sentencia del expediente $\mathrm{N}^{\circ} 00655$ 2010-PHC/TC y la Resolución de aclaración de 10 de diciembre de 2010. El Tribunal Constitucional se refiere: $a$ ) al debido proceso y a alguna de las formas de violación de dicho principio (inciso $3^{\circ}$ del artículo 139 de la Constitución); en tal razón analiza la prueba prohibida; $b$ ) alude a la presunción de inocencia (apartado e) del inciso 24, artículo $2^{\circ}$ de la Constitución) y en este caso, el Tribunal lo esgrime como argumento para señalar que la prueba prohibida porque colisiona con dicho derecho; $c$ ) al examinar la prueba prohibida en la Constitución señala que las pruebas expresamente prohibidas afectan al derecho a la intimidad (inciso 10 del artículo $2^{\circ}$ de la Constitución), es decir al secreto y a la inviolabilidad de sus comunicaciones y documentos privados, y finalmente examina el derecho a la libertad y a la seguridad personales (apartado 10 del inciso 24, artículo $2^{\circ}$ de la Constitución).

Es decir, el Tribunal Constitucional, al examinar el proceso del expediente $\mathrm{N}^{\mathrm{o}}$ 00655-2010-PCH/TC, en su Sentencia no trata el derecho a la información ni mucho menos en su Resolución de aclaración; pues, como se sabe los hechos que determinaron, finalmente, con la detención de Quimper, entre otros derechos que surgieron esta el referido a la libertad de información que nuestra Constitución Política del Estado define en el inciso 4 del artículo $2^{\circ}$; pero sin embargo, en forma sorpresiva el Tribunal Constitucional concluye regulando, desde su perspectiva, el derecho Constitucional de la libertad de información, y reitera, en su aclaración fundado en el inciso 10) del artículo $2^{\circ}$ de nuestra Constitución; por lo que se hace necesario recordar la jurisprudencia del propio Tribunal Constitucional.

\subsection{Contenido de la libertad de información y expresión}

El Tribunal Constitucional, en el caso "Caja Rural de Ahorro y Crédito de san Martín”, expediente $\mathrm{N}^{\circ}$ 0905-2001-PA/TC, fundamento $9^{\circ}$, y después de señalar que el inciso 4 del artículo $2^{\circ}$, de la Constitución, reconoce de manera independiente las libertades de expresión e información, como dos derechos distintos y, por tanto, cada uno con un objeto de protección distinto y seguidamente nos explica el ámbito de protección y tutela que tienen estos derechos, y así define que: "la libertad de expresión garantiza que las personas (individual o colectivamente consideradas) puedan trasmitir y difundir libremente sus ideas, pensamientos, juicios de valor u opiniones, la libertad de 
información, en cambio, garantiza un complejo haz de libertades, que, conforme enuncia el artículo $13^{\circ}$ de la Convención Americana de Derechos Humanos, comprende las libertades de buscar, recibir y difundir informaciones de toda índole verazmente”.

Luego, en el fundamento 11, de la Sentencia antes referida, nos explica cuales son las dimensiones de la libertad de información: “ $a$ ) el derecho de buscar o acceder a la información, que no sólo protege el derecho subjetivo de ser informado o de acceder a las fuentes de información, sino, al mismo tiempo, garantiza el derecho colectivo de ser informados, en forma veraz e imparcial, protegiéndose de ese modo el proceso de formación de la opinión pública y, en consecuencia, no sólo al informante, sino también a todo el proceso de elaboración, búsqueda, selección y confección de la información. $b$ ) la garantía de que el sujeto portador de los hechos noticiosos pueda difundirla libremente. La titularidad del derecho corresponde a todas las personas y, de manera especial, a los profesionales de la comunicación.

\subsection{El derecho a la información}

El derecho a la información, es un derecho fundamental constitutivo esencial de todos los instrumentos de derechos humanos y en especial de la Constitución Política del Estado, que como se demuestra con los antecedentes de nuestra Constituciones lo tenemos presente desde la Constitución de 1823, como libertad de prensa. Es un derecho que supone la información tanto recabarla como trasmitirla, nos dice Marcial Rubio ${ }^{3}$, y agrega que está formado por dos caras del derecho como consustanciales a su naturaleza; es un derecho que comprende de una parte el derecho de comunicar y de la otra parte, el derecho de recibir información. Dimensiones de la libertad de información, llama el Tribunal y refiere que son: a) el derecho de buscar o acceder a la información, que no sólo protege el derecho subjetivo de ser informado o de acceder a las fuentes de información, sino, al mismo tiempo, garantiza el derecho colectivo de ser informados, en forma veraz e imparcial, protegiéndose de ese modo el proceso de formación de la opinión pública y, en consecuencia, no sólo al informante, sino también a todo el proceso de elaboración, búsqueda, selección y confección de la información. b) la garantía de que el sujeto portador de los hechos noticiosos pueda difundirla libremente. El objeto protegido, en tal caso, es la comunicación libre, tanto la de los hechos como la de las opiniones. Por ello, tratándose de hechos difundidos, para merecer protección constitucional, requieren ser veraces, lo que supone la asunción de ciertos deberes y responsabilidades delicadísimas por quienes tienen la condición de sujetos informantes, forjadores de la opinión pública.

Así, el derecho de información, implica uno de los elementos sustantivos más relevantes que define la democracia, que constituye una condición esencial para la vigencia de ella y por tanto no se puede prescindir, pues, (...) garantiza el acceso, la

${ }^{3}$ Rubio Correa, Marcial. Estudio de la Constitución Política de 1993. Fondo Editorial de la PUCP. Lima 1999. Pág. 204. T 1. 
búsqueda y la difusión de hechos noticiosos o, en otros términos, la información veraz ${ }^{4}$. Veracidad para el Tribunal, desde una perspectiva constitucional, exige que los hechos difundidos por el comunicador se ajusten a la verdad en sus aspectos más relevantes; y verdad, en el fundamento 10 de la Sentencia ya señalada, el Tribunal Constitucional la define, citando Javier Cremades, como la adecuación aceptable entre el hecho y el mensaje difundido, la manifestación de lo que las cosas son. Se trata, pues, de la misma sustancia de la noticia, de su constitutivo. Por ello es un deber profesional del informador el respetar y reflejar la verdad substancial de los hechos.

Pérez Royo ${ }^{5}$, Maestro de Derecho Constitucional de la Universidad de Sevilla, recurriendo a una decisión del Tribunal Constitucional Español nos dice que la libertad de información es, en términos constitucionales, un medio de formación de la opinión pública en asuntos de interés general, cuyo valor de libertad preferente sobre otros derechos fundamentales viene determinado por su condición de garantía de la opinión pública, que es una institución consustancial al Estado democrático que los poderes públicos tienen especial obligación de proteger. Este valor preferente alcanza su máximo nivel cuando la libertad es ejercida por los profesionales de la información a través del vehículo institucionalizado de formación de opinión pública, que es la prensa, entendida en su más amplia acepción.

\subsection{La libertad de información y el mandato del Tribunal Constitucional en la Sentencia del Expediente $\mathbf{N}^{\circ}$ 00655-2010-PHC/TC.}

En el fundamento 15 de la Sentencia Caso "Caja Rural de Ahorro y Crédito de San Martín”, ha determinado que (...) conforme se desprende del artículo $2^{\circ}$, inciso 4), de la Constitución vigente, cuando, como consecuencia del ejercicio de las libertades informativas, se transgreden otros derechos constitucionales, como los derechos al honor o a la buena reputación, su tutela no puede significar que, con carácter preventivo, se impida a que un medio de comunicación social, cualquiera que sea su naturaleza, pueda propalar la información que se considera como lesiva, pues ello supondría vaciar de contenido a la cláusula que prohíbe la censura previa, la que proscribe el impedimento del ejercicio de tales libertades y, con ellos, la condición de garantía institucional de las libertades informativas como sustento de un régimen constitucional basado en el pluralismo ${ }^{6}$.

El Tribunal ha explicitado que los derechos al honor o a la buena reputación, mediante la libertad de información no quedan desprotegidos o en un absoluto estado de indefensión, pues, en tales casos, dice que el propio ordenamiento constitucional ha

${ }^{4}$ Sentencia en el caso "Caja Rural de Ahorro y Crédito de San Martín” expediente No 0905-2001-PA/TC., fundamento 9.

${ }^{5}$ Pérez Royo, Javier. Curso de derecho Constitucional. Ed. Marcial Pons. Madrid 2000. Pág. 437.

${ }^{6}$ El subrayado, es nuestro. 
previsto que sus mecanismos de control tengan que actuar en forma reparadora, mediante los diversos procesos que allí se tiene previsto; este criterio, sigue lo ordenado por la Convención Americana sobre Derechos Humanos, en su artículo 13.2 que dispone "El ejercicio del derecho a la libertad de pensamiento y de expresión, no puede estar sujeto previa censura sino a responsabilidades ulteriores, las que deben estar expresamente fijadas por la ley y ser necesarias para asegurar:

a) El respeto a los derechos o a la reputación de los demás, o

b) La protección de la seguridad nacional, el orden público y la salud o la moral públicas.

Asimismo, Tribunal Constitucional, en la Sentencia ya citada, ha seguido a la Corte Interamericana de Derechos Humanos en "La opinión consultiva OC-5/85 del 13 de noviembre de 1985”, solicitada por el Gobierno de Costa Rica. En dicha opinión, en el párrafo 38, señala que el artículo 13.2 de la Convención prohíbe la censura previa, y en el párrafo 39, nos dice que "El abuso de la libertad de expresión no puede ser objeto de medidas de control preventivo sino de responsabilidad para quien lo haya cometido.

Está claro que conforme a la Convención Americana de Derechos Humanos, a la Corte Interamericana de Derechos Humanos y jurisprudencia del Tribunal Constitucional, todo control o medida o censura previa, que se pretenda poner es siempre incompatible con el libre ejercicio del derecho a la información significa; en todo caso, cualquier medida es posterior, así lo dispone la Constitución Política del Estado en el artículo 2.4, disponiendo que los delitos cometidos con motivo del ejercicio del derecho a la información se tipifican en el Código Penal.

\section{Reflexiones finales}

La Resolución del Tribunal Constitucional, señala que de oficio aclara el fundamento 23 de la sentencia del caso "Quimper, expediente $\mathrm{N}^{\circ}$ 00655-2010-PHC/TC", en su punto $4^{\circ}$ de la Resolución de la aclaración dice "Que en relación a la interceptación de las telecomunicaciones y su divulgación por los medios de comunicación, está prohibida la difusión de información que afecte la intimidad personal o familiar, o la vida privada del interceptado o terceras personas, salvo que ella sea de interés o relevancia pública, lo que debe ser determinado en cada caso por el medio de comunicación. En caso de exceso tanto el periodista, como los editores y/o los propietarios de los medios de comunicación, serán responsables por tales excesos, según lo determine la autoridad competente".

Al respecto, el Tribunal no puede establecer ninguna responsabilidad, ni mucho menos señalar responsables en la comisión de un delito con motivo del ejercicio del derecho a la información, en todo caso ello es materia del juez penal. 
El Tribunal Constitucional, en su fundamento $5^{\circ}$, sostiene que “(...) corresponde precisar, de oficio, lo que debe ser sancionable es la conducta de quienes promueven, instigan o participan en la interceptación de las telecomunicaciones, aun cuando sean periodistas, medios o empresas dedicadas a las telecomunicaciones” y en tal sentido recuerda el artículo 2.10, que se refiere al secreto y a la inviolabilidad de sus comunicaciones y documentos privados, y que no tiene efecto legal los documentos privados obtenidos con violación de este precepto.

Ahora, cabe también recordar que en el contexto que argumenta el Tribunal, esta implícitamente contenido el derecho a la información y el tratamiento a este derecho, como ya se ha señalado en el punto 3.2, No es aceptable de ninguna forma la censura o medida previa que pueda enervar su ejercicio; la comisión de un delito que violente derechos de las personas, es de conocimiento del juez penal. El Tribunal no puede precisar tipificando conductas penales, reiteramos que es el juez penal el encargado de tipificar y sancionar la conducta de las personas que violan la intimidad personal.

Finalmente, el fundamento $20^{\circ}$ de la sentencia materia de nuestro análisis, que no ha sido materia de aclaración y que sigue vigente, contiene dos graves asuntos que seguro debe preocupar a las personas que desean y luchan por una auténtica democracia representativa, efectivamente en la segunda parte de este argumento el Tribunal considera que "el Estado debe investigar, juzgar y, en su caso sancionar a los responsables de la violación del derecho a la vida privada del beneficiario, consistente en la interceptación y divulgación de sus conversaciones telefónicas, así como la entrega de las conversaciones telefónicas a los medios de comunicación. Asimismo, debe precisarse que la divulgación de las grabaciones telefónicas requiere de la autorización de sus interlocutores para que se legítima ${ }^{7}$.

Es decir que de una parte el Tribunal solicita sanción para los responsables de la violación del derecho a la vida privada del beneficiario (Alberto Quimper Herrera), lo que parece correcto; en todo caso su invocación debió ser general, pero lo grave del acápite está en la parte final cuando dice: "precisarse que la divulgación de las grabaciones telefónicas requiere de la autorización de sus interlocutores para que se legítima”. Esta precisión es inconstitucional, pues cualquier control, en el marco del derecho a la información, es posterior y así lo determina nuestra Constitución Política del Estado en el artículo 2.4, que determina nuestro derecho a las libertades de información, opinión, expresión y difusión del pensamiento mediante la palabra oral o escrita o la imagen, por cualquier medio de comunicación social, sin previa autorización ni censura ni impedimento algunos, bajo responsabilidades de ley.

\footnotetext{
${ }^{7}$ Subrayado, nuestro.
} 